\title{
The Study on Construction Quality Control of Urban Rail Transit Project
}

\author{
Weifang Li \\ School of Management, Wuhan University of Science and Technology, Wuhan, 430081, China \\ wustlwf@163.com
}

Keywords: Urban rail transit project; Construction quality; Quality control; Controlled system

\begin{abstract}
As a type of public transportation tool, urban rail transit attracts people's attention since. With the development of urbanization, urban rail industry's has developed fast in China. For better development urban rail transit project, quality of urban rail transit project need be controlled. The quality of stages of construction has a direct impact on the final quality of the project. To strengthen the quality management of construction is a key to success of urban rail transit project. First of all it briefly introduces some related concepts and theories about the quality control of construction in the paper, it is clearly defined to analysis its features and basis of construction quality of urban rail transit project. Secondly, based on the above experimental results, the construction quality control system of urban rail transit project is constructed in the paper, defined the principles and aims of construction quality control, organizations and main function, process control and management. Finally, some main control points and control measures have been presented in the paper.
\end{abstract}

\section{Introduction}

Urban rail transit showed up in the world long before, as a type of public transportation tool, it gains popularity rapidly now. The urban rail transit projects are thrashed out no doubt in large cities throughout China. The urban rail transit projects are favorable for residents travel, harmonious and economy of the areas along the line. With large construction scale, there are many indexes concerned and factors considered, so it is hard to ensure the urban rail transit project quality. It is imperative to strengthen construction quality control of the urban rail transit project. Because of construction stage deciding on the project entity quality, the construction quality control is a key to success of urban rail transit project.

\section{Some Relevant Theoretical Foundations about Construction Quality Control of Urban Rail Transit Project}

Urban Rail Transit Project. Urban rail transit project is a collective conception, it is through the city and urban areas, it is a quick way traffic, moving vehicles of rail transit by electric traction, with higher execution speed, high concentrations, medium capacity. According to characters and ability, there are many kinds, including city's subway, light rail, light rail, monorail traffic, Tramcar, magnetically levitated train, and so on[1].

The Influencing Factor and the Main Contents of the Construction Quality Control. There are five major social factors, such as personnel, machinery, material, method, link in the construction quality control. On five respects, some corresponding measures should be taken in order to control the construction quality. (1) Human control. As the implementation main part of the project, human is a predominant in the engineering construction. There are the following main control ways.1)The quality of the leader. The quality of the leader has big effect on construction quality of the project. It is one of the vital factors to guarantee the construction quality and reliability. 2) Constructor knowledge and technical skills. These two elements determine whether constructors can finish their qualified tasks, which has a significant impact in construction quality of the project[2]. 3) People's mental behavior. People's physical act is affected as people's psychological directly or indirectly. (2) Control measures on construction materials. Project is composed of construction materials, material quality decides 
construction quality[3]. (3) Control measures on machine. Machinery equipment need to meet demands of construction requires and vary parameters. It is also a key to construction quality[4]. (4) Control measures on construction methods. Selecting effective construction methods could help achieve effective construction work, achieve the expectation good project standard. (5) Control measures on environmental factors. the project construction would be affected a lot of environmental factors, if the the influence of environmental factors cannot be overcome, the project is difficult to carry on smoothly.

The Characteristics of Construction Quality of Urban Rail Transit Project. (1)The large construction scale and the high investment. Urban rail transit project usually has several hundred or thousands of kilometers, 400-600 million RMB per kilometer cost. (2)Construction difficulty and the higher the security risk. Urban Rail Transit Project is mostly in the underground construction, the conditions of underground are very difficult for the public to predict and control, which further increases difficulties of construction quality of urban rail transit project. (3)Difficult coordination. With narrow and complex working platform, coordination of construction of urban rail transit project becomes more difficult.

Main Basis of Construction Quality of Urban Rail Transit Project. There are some main basis of construction quality of urban rail transit project, such as laws, and similar standards and principles in the countries, construction drawing papers, project's contract and construction documents, and so on.

\section{The Designs of the Construction Quality Control System of Urban Rail Transit Project}

The Control Principles and Targets of the Construction Quality Control of Urban Rail Transit Project. The control thought of the construction quality control of urban rail transit project determine some quality standards for installation which should be observed, targets to be achieved of the project.

The Basic Principles on the Construction Quality Control of Urban Rail Transit Project. (1)Adhere to the Quality first. (2)Focus on customers. (3)Insist on putting the prevention. (4)Keep a high standard quality and pass strict inspection. (5)Comply with the professional ethics[5].

The Organizations and Main Function of the Construction Quality Control of Urban Rail Transit Project. (1)Project Manager. Project manager should set up organizations of the construction quality control according to the quality principles and targets of the construction quality control of urban rail transit project, reasonable adjust of resources, hold regular conference about quality engineering with communication feedback. (2)Vice project manager. The responsibilities of Vice project manager are assisting project manager for schedule management, being responsible for their work within the scope. When the project manager is absent, his duties devolve upon the Vice project manager. (3)Chief engineer. Chief engineer is generally responsible for various technologies works and the control managements of process files and so on. Chief engineer holds regular technology meetings in order to give control back to the relevant technical problems and offering solutions. (4)General quality inspector. General quality inspector should be responsible for construction quality check-up, develop timely quality analysis, formulate timely and effective measures for improvement. General quality inspector is responsible for engineering quality inspection as leader.(5)Producing department. Producing department is responsible for management and coordination of production. During the construction process, if project quality cannot be ensured, Producing department should notify suspension for amendments. Then construction is followed when project quality cannot be ensured. (6)Engineering department. Engineering department is directly responsible for construction quality. Engineering department organizes construction employees to conduct technical disclosure before the construction. During construction, Engineering department examines each process and order notification to make corrections when deviation is detected. (7)Survey party. Survey party is responsible for measure components which are need to measure. Survey party should ensure accuracy of all kinds of measure tools, and be responsible for the results of their measure. (8)Materials department. Materials department is directly responsible for the raw material control, with raw material identity, keeping, maintenance and other aspects of work. Materials department is also responsible for the engineering device configuration, normal running and treatment of trouble etc. (9)Laboratory. Laboratory is responsible for experiment with access materials by regulation in order to ensure materials meeting practical engineering 
requirements. Laboratory is also responsible for experimental data and inspection materials. (10)Quality controlling office. Quality controlling office should fully carry out the system of Three Checking. Quality controlling office is responsible for dealing with returns, maintaining and rectification. Quality controlling office should do inspection record kept and develop QC group activity. (11)Quality inspection department. Quality inspection department is responsible for quality tests during construction[6].

The Process Control and Realization of Construction Quality of Urban Rail Transit Project. (1)The training quality control. Construction site personnel should have quality consciousness, which is good at good results for quality control. So quality awareness of construction site personnel should be strengthened by training through a period of time. Urban Rail Transit Project has longer construction period, many participators, so it is an integral part to improve quality levels of constructor[7]. (2)Construction materials control. Construction materials control is directly determining the quality assurance capability of urban rail transit project. Quality should be strictly controlled on the selection of materials. (3)Standard construction procedure. Construction procedure should be strictly regulated. Each part of the engineering construction should strictly obey the ways showed in flow chat of construction procedure. (4)Establish the system of quality responsibility management. Establish the system of quality responsibility management. Urban rail transit project is usually financed by government, with huge investment, long cycle of construction and benefit to the public. So project quality is a priority. People are vital part of the construction, some corresponding systems must be made up to get effective management for people. So it is indispensable to establish the system of quality responsibility management. Each builder and manager should need to have very clear responsibilities and rights, which make quality works become more accurate. Of course, the project manager is first responsible for project quality. (5)Carry out quality control unit events. Quality control unit is also known as QC unit, it means that staff members from different departments gather and form into unit according to quality requirements and some problems laying in site. Its purpose are improving problems and efficiency. During the urban rail transit project construction, QC units should be formed for key quality problems, discuss problems and put forward the measures and suggestions on improvement[8].

\section{Some Main Control Points and Control Measures}

Person's Conduct Control. Each worker has many different such as skill level, mental quality, environment fit, which decide different jobs. In the actual project, according to made on a 'case by case' basis, comparable worker should dictate what jobs they go for. It is very important to use human resources rationally.

Material's and Equipment's State Control. During the urban rail transit project construction, the category of the building material is numerous, amount used is huge, construction machinery are large-scale, measurement instruments require high accuracy, so it is It is very important to control material's and equipment's state. Material should be strictly controlled in the selection of provider and test. Construction machinery should be strictly controlled in choosing the type, entrance and operation. Measuring instruments precision should be selected by norms and standards[9].

Key Processes Control. The quality of key processes directly affects the quality of the project quality. So it is It is very important to control the key processes during the urban rail transit project construction, such as segment assembly, craftsmanship and pouring concrete in shield tunneling.

New Process and New Technology Control. With the development of urban rail transit project in china, lots of new process and new technology occur in the project. Builders who use new process or new technology should be trained and taken up their jobs by examination. The engineering which use new process or new technology should be tested more rigorously and following repair.

\section{Summary}

As a growth industry in architecture field in china, the urban rail transit project is blowout. Construction is important link of forming project entity. The construction quality control of urban rail transit project is 
a vast exercise, complicated and integrative systematic project, it will be perfect with long-term practice and study.

\section{References}

[1] .T.Fang, The study on management and quality control of survey and construction of urban rail transit projects, Guangzhou Architecture, 2006(5):11-13.

[2] F.Yang, The study on quality control of water diversion project construction, $\mathrm{Xi}$ an University of Technology Master's Thesis, 2018.8-7.

[3] Arditi D, Gunaydin H.Total quality management in the construction process, International Journal of Project Management ,1995,15(4):235-243.

[4] H.Y.Wang, The study on the construction quality management of urban rail transit projects construction, 2015.5(20):160-163.

[5] G.Y.Cheng, The study on quality control of big shield segment of crossing the river of urban rail transit projects, Nanjing University of Science \& Technology Master's Thesis, 2013.14-22.

[6] D.J.Huang, J.Li, The difficulty and control of installation and construction of contact rail, Railway Standard Design, 2008(7):46-48.

[7] X.W.Ren, The study on quality and safety supervision model of construction of urban rail transit projects in Nanjing, Southeast of University Master's Thesis, 2014.19-48.

[8] Y.Gu, The study on system of quality management of urban rail transit projects construction, Beijing Jiaotong University Master's Thesis, 2006.10-20

[9] Sebastian K,Damian D.Method of assessing the quality of the design process of construction equipment with the use of DESS, Automation in Construction, 2012,22: 223-232. 